\title{
PRÁTICA DE EDUCAÇÃO EM SAÚDE PERCEBIDA POR ESCOLARES
}

Cícero Tavares Leite', Roberta Peixoto Vieira² ${ }^{2}$ Caroline Antero Machado ${ }^{3}$, Glauberto da Silva Quirino ${ }^{4}$, Maria de Fátima Antero Sousa Machado ${ }^{5}$

RESUMO: Estudo quantitativo realizado com 571 estudantes, de 14 a 19 anos de idade, do Ensino Médio de três escolas públicas com o objetivo de descrever percepções de escolares sobre a prática de educação em saúde na escola. A coleta ocorreu após o aceite dos adolescentes e responsáveis legais, de fevereiro a março de 2012, através de questionários com perguntas objetivas, organizados no software Statistical Package for Social Sciences 18.0, com apresentação descritiva, frequencial e em tabelas. Os resultados apontaram que 59\% reconheceram a existência de momentos educativos em saúde, abordando a sexualidade (61,5\%), álcool e drogas (59,6\%). Para 43\% não houve escuta qualificada antes das atividades, $66 \%$ não reconheceram a participação da Estratégia Saúde da Família e para 56\% as intervenções pedagógicas foram avaliadas como insatisfatórias. Conclui-se que a Estratégia Saúde da Família deve atuar junto aos adolescentes para o fortalecimento de vínculos com este público. DESCRITORES: Adolescente; Educação em saúde; Educação primária e secundária; Promoção da saúde.

\section{PRÁCTICA DE EDUCACIÓN EN SALUD PERCIBIDA POR ESTUDIANTES}

RESUMEN: Estudio cuantitativo realizado con 571 estudiantes, de 14 a 19 años de edad, de la Enseñanza Medio de tres escuelas públicas con el objetivo de describir percepciones de escolares sobre la práctica de educación en salud en la escuela. Los dados fueron obtenidos después que los adolescentes y responsables legales autorizaron, de febrero a marzo de 2012, por medio de cuestionarios con preguntas objetivas, organizados en software Statistical Package for Social Sciences 18.0, con presentación descriptiva, frecuencial y en tablas. Los resultados apuntaron que 59\% reconocieron la existencia de momentos educativos en salud, abordando la sexualidad (61,5\%), alcohol y drogas (59,6\%). Para 43\% no hubo escucha cualificada antes de las actividades, 66\% no reconocieron la participación de la Estrategia Salud de la Familia y para 56\% las intervenciones pedagógicas fueron evaluadas como insatisfactorias. Se concluye que la Estrategia Salud de la Familia debe actuar junto a los adolescentes para el fortalecimiento de vínculos con este público.

DESCRIPTORES: Adolescente; Educación en salud; Educación primaria y secundaria; Promoción de la salud.

\section{HEALTH EDUCATION PRACTICE AS PERCEIVED BY SENIOR HIGH STUDENTS}

ABSTRACT: This quantitative study was undertaken with 571 students aged between 14 and 19 years old from three state senior high schools, aiming to describe the students' perceptions regarding the practice of health education in the school. Data collection occurred following the acceptance of the adolescents and those legally responsible for them, between February and March 2012, through questionnaires with objective questions, organized using the Statistical Package for Social Sciences software, version 18.0, with data presented through description, frequency and in tables. The results indicated that (59\%) recognized the existence of times of health education, addressing sexuality (61.5\%), and alcohol and drugs (59.6\%). According to those studied, $(43 \%)$ asserted that there had been no qualified listening prior to the activities, $(66 \%)$ did not recognize the participation of the Family Health Strategy, and 56\% evaluated the pedagogical interventions as dissatisfactory. It is concluded that the Family Health Strategy must work alongside the adolescents so as to strengthen the bonds with this public.

DESCRIPTORS: Adolescent; Health education; Education, primary and secondary; Health promotion.

${ }^{1}$ Acadêmico de Enfermagem. Universidade Regional do Cariri. Bolsista CNPq. Barbalha-CE-Brasil

${ }^{2}$ Enfermeira. Especialista em Saúde da Família. Professora daUniversidade Regional do Cariri. Barbalha-CE-Brasil ${ }^{3}$ Cirurgiã-dentista. Mestre em Saúde Coletiva. Professora da Faculdade Maurício de Nassau. Fortaleza-CE-Brasil

${ }^{4}$ Enfermeiro. Doutor em Educação em Ciências: Química da Vida e Saúde. Professor da Universidade Regional do Cariri. Barbalha-CE-Brasil ${ }^{5}$ Enfermeira. Doutora em Enfermagem. Professora da Universidade Regional do Cariri e da Escola de Saúde Pública do Ceará. Fortaleza-CE-Brasil 


\section{INTRODUÇÃO}

A adolescência é uma das surpreendentes etapas da vida do ser humano que se caracteriza por alterações biopsicossociais intensas, percebidas e vivenciadas de maneira diferenciada, com interpretações e tratamento distintos, a depender da cultura em que o indivíduo esteja inserido $^{(1)}$. O campo de estudo sobre a adolescência destacou-se nas últimas décadas em decorrência do aumento desta população e por questões que a envolvem e causam preocupação, como gravidez não planejada, infecções sexualmente transmissíveis (IST/ aids), mortes violentas por armas de fogo, violência no trânsito e uso de drogas lícitas e ilícitas ${ }^{(2)}$.

Em face às vulnerabilidades pelas quais essa população possa estar exposta, surgiu a necessidade da implantação de políticas públicas que não contemplasse a saúde do adolescente apenas na perspectiva biomédico-curativista, mas, de maneira integral. Logo, a Estratégia Saúde da Família (ESF) deve atender esta prerrogativa ampliada de cuidados. Esta Estratégia representa um avanço para a promoção da saúde deste público, contudo, ela ainda não apresenta ações programadas ou sistematizadas para atender ao adolescente ${ }^{(3)}$. Sob esta ótica, urge a necessidade de desenvolver ações intersetoriais e a escola passou a ser considerada lócus do cuidado no contexto da Promoção da Saúde.

Em um sentido amplo, a promoção da saúde refere-se à conquista do poder técnico (capacidade) e da consciência política das comunidades (empower$m e n t$ ) para resolução de problemas pelos indivíduos e comunidade, na busca por criar ambientes favoráveis à saúde e que propiciem igualdade de oportunidades para que todos realizem de forma plena seu potencial de saúde ${ }^{(4)}$. Nesta filosofia, as ações educativas em saúde devem ser planejadas e direcionadas ao público-alvo adequado, articuladas por equipe multiprofissional e executadas permanentemente, considerando o que os sujeitos precisam e desejam saber para que se promova sua saúde.

Deste modo, o processo de educação em saúde utiliza ferramenta essencial no seu escopo de trabalho a comunicação, a qual deve consistir em uma retroalimentação que possa favorecer a construção do conhecimento, habilidades para que o público adolescente realize escolhas a partir de uma consciência crítica, pautada em medidas que modifiquem o status quo e leve os atores a participarem do processo ${ }^{(5)}$.

A educação em saúde enquanto um processo, um pensar, um fazer pedagógico emancipatório, ou seja, na possibilidade do desenvolvimento da autonomia intelectual dos sujeitos, individual e coletiva, envolve maior aproximação com o adolescente, visto que devem ser consideradas as particularidades de cada grupo, bem como, o entorno social onde eles estão inseridos. Dessa forma, a proposta deste estudo partiu de uma pesquisa realizada na cidade de Barbalha-Ceará, Brasil com escolares. Essa mostrou que eles não reconhecem a ESF como um espaço promotor de saúde, mas, apenas como resolutiva de problemas centrados na doença, não existindo momentos voltados para este público nas unidades básicas de saúde, os quais enfocassem a educação em saúde como uma ferramenta emancipatória para a promoção da saúde ${ }^{(6)}$.

Ante a estas constatações, inquietou-nos quanto à outra vertente que também pode trabalhar a educação em saúde para o adolescente, a escola, uma vez que esta deve atuar como partícipe na formação de sujeitos imbuídos no processo da cidadania e da aprendizagem em saúde. Portanto, além de ser atual, trabalhar a temática que ora se propõe é fundamental para a formação de juventude cidadã e, neste sentido, o enfermeiro é agente primordial no processo didático-pedagógico em saúde transformador.

Do exposto, o objeto de estudo foi delineado a partir das seguintes perguntas norteadoras: as escolas promovem momentos voltados para a educação em saúde para os adolescentes? Quais as temáticas trabalhadas? Os adolescentes são consultados previamente? Qual a participação da ESF? Quais as tecnologias utilizadas? Sob esta ótica, este estudo teve como objetivo descrever as percepções de adolescentes escolares sobre a prática de educação em saúde na escola.

\section{MÉTODO}

Pesquisa de natureza quantitativa, realizada em três escolas públicas de Ensino Médio, pertencentes à rede Estadual de Barbalha-Ceará, Brasil. O município possuía três escolas públicas de Ensino Médio, situadas na zona urbana, registradas na $19^{\mathrm{a}}$ Coordenadoria Regional de Desenvolvimento da Educação (CREDE 19). A escolha do cenário da pesquisa deveu-se as escolas fazerem parte de um projeto em parceria com a CREDE 19, denominado "Professor Diretor de Turma" que tinha como objetivo trabalhar com os adolescentes questões sobre sexualidade, infecções sexualmente transmissíveis (IST), prevenção do uso de drogas, e de aproximação da escola com a comunidade.

Cada escola contava, respectivamente, com 958, 
774 e 360 alunos, perfazendo o total 2.118 alunos matriculados. Para o cálculo do tamanho da amostra utilizou-se a amostragem aleatória por conglomerado, que deve ser utilizada quando a população apresenta-se subdivida em pequenos grupos ou conglomerados ${ }^{(7)}$. A seleção da amostra foi proporcional ao número de alunos de cada uma delas, o que correspondeu respectivamente a 212,199 , e 160 alunos, perfazendo 571 estudantes.

A coleta de dados ocorreu de fevereiro a março de 2012, mediante utilização de questionários com questões objetivas. As variáveis investigadas foram: idade, sexo, estado civil, existência de momentos educativos em saúde na escola, inserção da ESF na escola, profissional que conduziu as atividades, materiais utilizados e avaliação dos momentos educativos realizada pelos adolescentes.

Após anuência da coordenação de cada uma das escolas os professores cederam um momento durante as aulas para que o pesquisador pudesse explicar o objetivo da pesquisa e os Termos de Consentimento Livre e Esclarecido e Pós-esclarecido, juntamente com os questionários para serem levados para casa pelos adolescentes. Solicitou-se a autorização dos pais, ou responsáveis legais, através da assinatura dos termos de pós-esclarecido, no caso dos menores de 18 anos de idade.

Na ocasião, foram distribuídos, respectivamente nas escolas, 318, 299 e 240 questionários, ou seja, $50 \%$ a mais em relação à amostra calculada, tendo em vista as possíveis perdas com alunos faltosos, ou por outros motivos. Estabeleceu-se o prazo de uma semana para recolhimento dos mesmos. Deste modo, foi necessário voltar às escolas três vezes consecutivas até se completar a amostra. Os critérios de inclusão no estudo foram: ser adolescente (10 a 19 anos de idade) e entregar o questionário durante o período de coleta de dados.

Para validação do instrumento de coleta aplicou-se um teste piloto em outra escola com características semelhantes às do estudo, resultando na readequação do questionário. A organização dos dados ocorreu mediante utilização do software Statistical Package for Social Sciences 18.0 com a apresentação dos resultados de forma descritiva, frequencial e em tabelas, seguindo-se à análise e discussão dos dados com o suporte da literatura com foco nas temáticas, adolescente e educação em saúde. O estudo obedeceu à Resolução 196/96 ${ }^{(8)}$, para tanto, obteve parecer favorável do Comitê de Ética em Pesquisa da Universidade Regional do Cariri protocolo n. 98/2011.

\section{RESULTADOS}

A amostra deste estudo foi constituída por 571 alunos distribuídos em três escolas, denominadas de escolas A, B e C, e contou, respectivamente, com 212, 199 e 160 adolescentes. Quanto ao sexo, 217(38\%) pertenciam ao sexo masculino e $354(62 \%)$ ao feminino. A média de idade dos participantes no estudo foi de $16,59( \pm 1,27)$, variando de 14 a 19 anos de idade. Com relação ao estado civil, 553(97,5\%) declararam-se solteiros, $14(2,5 \%)$ casados ou em união estável e $4(0,7 \%)$ não informaram.

Quando questionados a respeito da existência de momentos voltados para temáticas educativas em saúde na escola, 337(59\%) afirmaram que esses momentos existiram, $231(40,5 \%)$ não reconheceram estes momentos e 3(0,5\%) não informaram. Em tais momentos, verificou-se que a escola abordou temáticas relacionadas, principalmente, à sexualidade e ao uso de álcool/drogas.

Segundo os adolescentes pesquisados, as temáticas abordadas nas escolas foram: sexualidade, 392(61,5\%); álcool e drogas, 340(59,6\%); contracepção, 164(28,8\%); saúde bucal, 61(10,7\%); e distúrbios alimentares, $15(2,3 \%)$. A somatória ultrapassou $100 \%$, tendo em vista que eles podiam assinalar mais de uma opção, o mesmo aconteceu com outras variáveis presentes no estudo. Todos os temas apontados pelos adolescentes estavam presentes no instrumento aplicado.

Segundo os adolescentes pesquisados a escolha dos temas abordados nas atividades educativas em saúde, 245(43\%) mencionaram que os profissionais da saúde ou educação não os consultaram para conhecer suas opiniões e necessidades; $143(25,1 \%)$ afirmaram que os profissionais perguntaram diretamente aos alunos acerca do que desejavam que fosse abordado; $136(23,9 \%)$ apontaram que os profissionais realizaram dinâmicas para a sondagem dos temas; e 104(18,2\%) mencionaram a utilização de caixas para sugestão.

Verificou-se, também, que as temáticas trabalhadas encontravam-se em conformidade com o interesse dos adolescentes, os quais demonstraram maior interesse pelas temáticas: sexualidade, 344(60,4\%); álcool/drogas, 225(39,5\%); métodos contraceptivos, 79(13,9\%); e saúde bucal, 61(10,7\%).

Sobre a inserção dos profissionais da ESF na escola, observou-se relativa ausência destes, visto que a maior parte dos adolescentes, 337(66,8\%), afirmou que os mesmos nunca visitaram a escola (Tabela 1). 
Tabela 1- Frequência dos profissionais da Estratégia Saúde da Família na escola. Barbalha-CE-Brasil, 2012

\begin{tabular}{lcc}
\hline Variável & n & $\mathbf{\%}$ \\
\hline Nunca visitou a escola & 377 & 66,0 \\
Visitou uma única vez & 108 & 19,0 \\
Visita a escola frequentemente & 79 & 13,8 \\
Não informaram & 7 & 1,2 \\
\hline Total & $\mathbf{5 7 1}$ & $\mathbf{1 0 0}$ \\
\hline
\end{tabular}

Entre os profissionais que realizaram ações educativas em saúde para adolescentes nas escolas, eles citaram: professores das próprias escolas, 201(35,2\%); enfermeiros, 161(28,3\%); seguidos pelos Agentes Comunitários de Saúde (ACS), 98(17,2\%); cirurgiões dentistas, 10(1,8\%); médicos, 9(1,6\%); e 92(15,9\%) não informaram.

Para a condução dos momentos educativos em saúde, os adolescentes identificaram o uso de vídeos, 368(64,7\%); cartazes, 173 (30,4\%); gincanas, 41(47,2\%). Em relação aos momentos educativos em saúde, segundo a percepção dos adolescentes escolares, 234(41\%) classificaram como bom; $320(56 \%)$ como insatisfatório e $17(3 \%)$ não informaram.

\section{DISCUSSÃO}

A sexualidade parece soar como uma curiosidade dos adolescentes em obter mais informações sobre esse assunto, embora não tenha consistido em objeto de investigação a forma como os professores a abordavam na escola, nem a dimensão com que a mesma apareceu no estudo.

Neste sentido, os adolescentes colocaram esta temática como prioridade e, intrinsecamente, apontaram a escola como intermediadora para tratar desse assunto. Isto sugere que eles se sentem à vontade naquele ambiente, talvez, por estarem em grupo e isso de algum modo oportunize aos professores o trabalho com este público. No entanto, isto não isenta a responsabilidade do diálogo no seio familiar, bem como, o compromisso da ESF enquanto detentora da corresponsabilidade de enfocar a educação sexual para esta clientela.

Nota-se que talvez haja abstenção ou distanciamento, tanto da família quanto da ESF, em assumir o papel da educação sexual para o adolescente. E a escola, muitas vezes, esbarra em dificuldades para tratar desse assunto, seja pela falta de vivência do professor em socializar a temática, devido à carência de recursos didático pedagógicos, ou por acreditarem que essa função não lhes compete ${ }^{(9)}$.
Saúde, escola e família devem unir-se para que o público adolescente supere as situações de vulnerabilidade e diminua a lacuna existente entre as ações voltadas à educação sexual e a necessidade apontada pelos atores que educam e cuidam desse grupo. Isso seria possível a partir do deslocamento dos constrangimentos de gênero e dos estereótipos que influenciam fortemente valores e atitudes das pessoas para uma dimensão inclusiva, cidadã e emancipatória que considere os aspectos históricos, sociais, políticos e culturais, para além da materialidade biológica e moral da sexualidade.

Essa assertiva é corroborada com outro estudo que mostrou que os professores não abordavam a sexualidade para o adolescente com ressalvas aos que estavam voltados para as ciências biológicas, e essa abordagem era direcionada ao biologicismo e higiene corporal, restritos aos conteúdos pedagógicos, sem que houvesse a preocupação em levantar outras questões vinculadas à sexualidade ${ }^{(10)}$. Percebe-se que a questão de gênero na sexualidade aos poucos ganha notoriedade em diversos segmentos da sociedade, através de discussões políticas, na mídia e no meio acadêmico.

Quanto à segunda temática, álcool e drogas, estudo mostrou o consumo de álcool por adolescentes precocemente, por volta dos 12 anos de idade, e esse ingresso tem sido motivado, principalmente, pela curiosidade, influência de amigos e também pelo desconhecimento dos prejuízos provocados por essas substâncias no organismo, no extrato familiar e social ${ }^{(11)}$.

Além das políticas públicas de prevenção e proteção a criança e ao adolescente são fundamentais ações de educação em saúde voltadas para esta temática. E a escola, ESF e família são detentoras de uma corresponsabilidade para com este público, cada uma a seu modo na preparação deste grupo, para superação das situações de vulnerabilidades e riscos que podem comprometer a integridade física, emocional e o convívio social dos adolescentes. Daí a necessidade da família manter um diálogo com o adolescente e de aproximar-se da escola. E esta, em contrapartida, deve abrir as portas para a comunidade onde está inserida e trabalhar a educação em saúde em consonância com as necessidades do entorno social apreendido.

Deste modo, para que as ações de educação em saúde sejam efetivas é importante considerar a opinião dos indivíduos envolvidos no processo, sem que haja imposição por parte do educador ou facilitador. E que este desenvolva habilidades de trabalho em equipe, criatividade e capacidade de comunicação como re- 
quisita o trabalho com adolescentes ${ }^{(12)}$. Assim, quando o processo acontece a partir de uma metodologia dialógica os sujeitos podem sentir-se motivados a querer participar e aprender.

A educação em saúde deve ser trabalhada na perspectiva da construção do conhecimento e aproveitar as experiências, a vivência dos sujeitos para os quais ela se volta, sem autoritarismos, possibilitando ao público alvo vivenciar mudanças de comportamento ${ }^{(13)}$.

A ESF, pela sua abrangência e aproximação com a comunidade, permite conhecer o perfil do seu público e direcione o seu escopo de trabalho, voltando-se para as necessidades apresentadas. Assim, ao considerar o adolescente como potencialmente vulnerável ela deve acolher este público e enfocar as ações de educação em saúde para ele. Estudo mostrou que a ESF reconhece o espaço escolar como ideal para a realização de ações de educação em saúde por proporcionar alcance do coletivo. Contudo, este espaço ainda é visto como substitutivo à lacuna não preenchida nas unidades de saúde e, na maioria, das vezes apresenta ações desarticuladas e sem continuidade na escola ${ }^{(14)}$.

O estudo citado anteriormente corrobora os dados encontrados nesta pesquisa, tendo em vista que a maioria dos adolescentes afirmou que a ESF nunca compareceu à escola, com exceção da participação isolada de alguns profissionais; dentre eles, o enfermeiro foi o mais evidenciado. Este profissional, por ter formação político-social voltada para o processo da educação em saúde e por assim assumir uma postura de agente transformador, aproxima-se das necessidades da comunidade e família, estendendo-se ao adolescente ${ }^{(15)}$.

No entanto, a responsabilidade de enfocar as ações de saúde para o adolescente é de todos da equipe. Para isto, é necessário ampliar o conhecimento por meio de estudos e práticas, aperfeiçoando o cuidado e educação com os adolescentes. Assim, a ESF quando presente com ações de educação em saúde na escola, de modo programado, conquista a confiança do adolescente por meio do vínculo de aproximação e possibilita a divulgação das ações que devem ser ofertadas a esta clientela nas unidades de saúde da família, podendo as ações ocorrer em paralelo com as atividades escolares.

Neste sentido, dado à importância das políticas públicas de atenção a saúde do adolescente, foi instituído, em 2007, o Programa Saúde na Escola em parceria com os Ministérios da Saúde e Educação do Brasil. Os objetivos consistem em promoção da saúde e prevenção de agravos; promover a comunicação entre escolas e unidades de saúde e assegurar a troca de conhecimentos das condições de saúde dos estudantes, dentre outros ${ }^{(16)}$.

Este programa apresenta-se como uma possibilidade para a promoção da saúde do adolescente. Desta forma, como mostrou um estudo realizado com profissionais da ESF, a estratégia ampliará o cuidado com a saúde do adolescente, sob um prisma voltado para a promoção da saúde com o objetivo de estreitar laços entre a saúde e educação ${ }^{(17)}$. Destaca-se que no contexto pesquisado, o município havia aderido ao programa, porém, as atividades referentes ao mesmo não haviam sido iniciadas até o momento em que os dados foram coletados. Nesta compreensão, é inegável que a implantação deste programa ampliará a atenção dispensada ao adolescente. Contudo, as ações nos processos educativos em saúde devem ser enfocadas para o adolescente em diferentes contextos, nas unidades de saúde, nas escolas e no seio familiar, não condicionado apenas a existência de um programa específico.

Entende-se que o adolescente é um ser dinâmico e que as ações educativas em saúde direcionadas a ele também deve seguir esse dinamismo para conquistar e manter o interesse deste público, seja na escola ou nas unidades de saúde da família. Assim, na perspectiva de atenção a saúde do adolescente, é indispensável a utilização das tecnologias leves em saúde, como a do acolhimento, rodas de conversa e escuta qualificada. Entretanto, outros artefatos, como filmes, matérias de revistas, jornais, dinâmicas e músicas podem ser considerados como adequados para serem trabalhados com adolescentes, por proporcionar socialização de discussões ao tempo em que permite, ao facilitador, avaliar a compreensão dos envolvidos acerca das temáticas propostas ${ }^{(18-19)}$.

Deste modo, o emprego de metodologias adequadas pode auxiliar na condução do processo de educação em saúde para o adolescente a partir de uma participação ativa e problematizadora em saúde. Com isto, o processo da educação em saúde para o adolescente deve partir da compreensão de uma participação habilitadora, ou seja, quando os sujeitos participam ativamente das discussões que envolvem suas vidas ${ }^{(5,19)}$. Nesta compreensão, o aprendizado deve ser enfocado sob uma perspectiva de diálogo, de aproximação, de escuta para se elaborar as atividades educativas em saúde, a partir das necessidades expressas pelos adolescentes.

\section{CONSIDERAÇÕES FINAIS}

O estudo aponta a existência de momentos de educa- 
ção em saúde nas escolas, sobressaindo-se a abordagem dos temas: sexualidade, álcool e drogas as quais estão alinhadas aos interesses dos adolescentes. Entretanto, quase metade destes não foram consultados sobre as temáticas que deveriam ser abordadas. Verificou-se a relativa ausência da ESF na escola sendo os momentos educativos conduzidos pelos professores e enfermeiros. Outro aspecto que merece ser destacado refere-se à abordagem dada pelos profissionais, avaliada como insatisfatória.

Sinaliza-se para a necessidade de articulação entre os profissionais da ESF e professores, envolvendo a família no que se refere ao trabalho com adolescentes com o objetivo de minimizar as situações de vulnerabilidade. Ademais, o cuidado colobarativo entre os setores Saúde e Educação possibilita a potencialização e eficácia das ações direcionadas ao adolescente nos processos de educação em saúde no contexto escolar.

Constatou-se, segundo os adolescentes pesquisados, a presença do profissional enfermeiro nas ações educativas em saúde nas escolas, no entanto, esta não envolvia a equipe e não acontecia de modo programado. Diante disto, reitera-se que as ações direcionadas ao adolescente devem ser programadas, articuladas multiprofissionalmente, tendo como foco as necessidades desse público, respeitando sua autonomia, instigando o aprendizado e assim proporcionar mudanças de comportamento que os conduza a uma vida saudável.

Deste modo, com estas reflexões pretende-se contribuir para o enriquecimento do conhecimento no campo da Enfermagem de modo a estabelecer parcerias com o contexto escolar, adolescente e família, na perspectiva de aproximação para a promoção da saúde.

\section{AGRADECIMENTOS}

Ao Conselho Nacional de Desenvolvimento Científico e Tecnológico- CNPq.

\section{REFERÊNCIAS}

1. Araújo AC, Lunardi VL, Silveira RS, Thofehrn MB, Porto AR. Transição da adolescência para a fase adulta na ótica de adolescentes. Rev. enferm. UERJ. [Internet] 2011;19(2) [acesso em 11 mar 2012]. Disponível: http:// www.facenf.uerj.br/v19n2/v19n2a18.pdf?.

2. Cromach FML, Burrsztyn I, Tura LFR. O olhar do adolescente sobre saúde: um estudo de representações sociais. Ciênc. saúde colet. [Internet] 2009;14(2) [acesso em 18 mai 2012]. Disponível: http://dx.doi.org/10.1590/ S1413-81232009000200031
3. Gomes MC, Horta CN. Promoção de Saúde do adolescente em âmbito escolar. Rev. APS. [Internet] 2010;13(4) [acesso em 08 mar 2012]. Disponível: http:// www.aps.ufjf.br/index.php/aps/article/ viewPDFInterstitial/897/394.

4. Bacheladenski MS, Júnior EM. Contribuições do campo do lazer para promoção da saúde. Ciênc. saúde coletiva. [Internet] 2010;15(5) [acesso em 12 fev 2012]. Disponível: http://dx.doi.org/10.1590/S141381232010000500031

5. Machado MFAS, Viera NSC, Silva RM. Compreensão das mudanças comportamentais do usuário no Programa Saúde da Família por meio da participação habilitadora. Ciênc. saúde colet. [Internet] 2010;15(4) [acesso em 13 jan 2012]. Disponível: http://dx.doi. org/10.1590/S1413-81232010000400027

6. Vieira RP, Machado MFAS, Bezerra IMP, Machado CA. Assistência à saúde e demanda dos serviços na Estratégia Saúde da Família: a visão dos adolescentes. Cogitare enferm. [Internet] 2011;16(4) [acesso em 13 jan 2012]. Disponível: http:// ojs.c3sl.ufpr.br/ojs2/index. php/cogitare/article/download/.../17065.|

7. Callegari SMJ. Bioestatística: princípios e aplicações. Porto Alegre: Artmed; 2003.

8. Ministério da Saúde (BR). Conselho Nacional de Saúde. Diretrizes regulamentadoras de pesquisa envolvendo seres humanos. Resolução no 196, de 10 de Outubro de 1996. Brasília; 1996.

9. Holanda LM, Frota MA, Machado MFAS, Vieira NC. O papel do professor na educação sexual de adolescentes. Cogitare enferm. [Internet] 2010;15(4) [acesso em 23 jul 2012]: Disponívem:http://ojs.c3sl.ufpr.br/ojs/index.php/ cogitare/article/download/20371/13540?.

10. Quirino GS, Rocha JBT. Sexualidade e Educação Sexual na percepção do docente. Educar em Revista. [Internet] 2012;(43) [acesso em 18 jul 2012]. Disponível: http://ojs.c3sl.ufpr.br/ojs2/index.php/educar/article/ view/25638/17616.

11. Bezerra IMP, Andrade RRMP, Machado CA, Machado MFAS. Prevalência do uso de álcool em estudantes de ensino médio. RBPS [Internet] 2011;24(1) [acesso em 18 jun 2012]: Disponível: http://www.redalyc.org/articulo. oa?id=40819112005.

12. Higarashi IH, Baratiere T, Rocher S, Marcon SS. Atuação do enfermeiro junto aos adolescentes: identificando as dificuldades e perspectivas de transformação. Rev. 
enferm. UERJ. [Internet] 2011;19(3) [acesso em 14 mar 2012]. Disponível: http://www.facenf.uerj.br/v19n3/ v19n3a06.pdf?.

13. Jahn AC, Guzzo PC, Costa MC, Silva EB, Guth EJ, Lima SBS. Educação popular em saúde: metodologia potencializadora das ações do enfermeiro. Rev. enferm. UFSM. [Internet] 2012;2(3) [acesso em 24 jul 2012]. Disponível: http://cascavel.ufsm.br/revistas/ojs-2.2.2/ index.php/reufsm/article/.../pdf|.

14. Santos AAG, Silva RM, Machado MFAS, Vieira LJES, Catrib HMF. Sentidos atribuídos por profissionais a promoção da saúde do adolescente. Ciênc. saúde colet. [Internet] 2012;17(5) [acesso em 13 jun 2012]. Disponível: http://dx.doi.org/10.1590/S1413-81232012000500021

15. Silva LD, Beck CLC, Dissen CM, Tavares JP, Budó MLD, Silva HS. O enfermeiro e a educação em saúde: um estudo bibliográfico. Rev. enferm. UFSM. [Internet] 2012;2(2) [acesso em 15 jul 2012]. Disponível: http:// cascavel.ufsm.br/revistas/ojs-2.2.2/index.php/reufsm/ article/view/2676.

16. Ministério da Saúde (BR). Secretaria de Atenção à Saúde. Departamento de Atenção Básica. Saúde na Escola. Brasília: Ministério da saúde; 2009.

17. Rabello SHS, Caldeira AMA, Teixeira F. Os artefatos dos media na educação em sexualidade. Rev. Exedra. [Internet] 2012;(6) [acesso em 25 ago 2012]. Disponível: http://www.exedrajournal.com/docs/N6/05-Edu.pdf.

18. Nogueira LA, Bandeira J, Santhyago MCG. Educação em saúde na atenção ao adolescente: relato de experiência. Em extensão. [Internet] 2012;(2) [acesso em 25 set 2012]. Disponível: http://www.seer.ufu.br/ index.php/revextensao/article/view/20788/11890.

19. Almeida KL, Machado MFAS, Machado LDS. Pesquisa de Base Comunitária (PPBC): Uma metodologia de participação de adolescentes. Cad. Cult. Cienc. [Internet] 2012;11(1) [acesso em 15 set 2012]. Disponível: http:// periodicos.urca.br/ojs/index.php/cadernos/ article/ view/489/pdf 